\title{
Positive Effects of Cholinergic Stimulation Favor Young APOE \&4 Carriers
}

\author{
Natalie L Marchant*,', Sarah L King', Naji Tabet ${ }^{2}$ and Jennifer M Rusted' \\ 'Psychology Department, University of Sussex, Brighton, East Sussex, UK; ${ }^{2}$ Brighton and Sussex Medical School, Institute of Postgraduate \\ Medicine, University of Brighton, Brighton, East Sussex, UK
}

\begin{abstract}
The potential of putative cognitive-enhancing compounds to improve mental processing both in healthy and vulnerable populations is an area of growing interest to scientific and clinical communities. The possible influence of individual genetic differences on efficacy of these compounds has yet to be considered. We sought to investigate the profile of young-adult apolipoprotein E (APOE) $\varepsilon 4$ carriers across cognitive domains given that possession of this gene variant increases risk of developing dementia in later life. We also explored whether APOE genotype interacts with the cognitive enhancer, nicotine. A total of I mg of the cholinergic agonist nicotine was administered through nasal spray to healthy non-smoking young adults (aged 18-30) with either $\varepsilon 3 / \varepsilon 3(N=29)$ or $\varepsilon 4$ (at least one $\varepsilon 4$ allele, $N=27$ ) genotype. Participants were matched on age, sex, and IQ in a placebo-controlled, double-blind 2 (drug: placebo, nicotine) $\times 2$ (genotype: $\varepsilon 3, \varepsilon 4$ ) between subjects design. Here, we show that, paradoxically, possession of the $\varepsilon 4$ allele confers a cognitive advantage on tasks mediated by the frontal lobe, and that young carriers of the $\varepsilon 4$ allele show larger cognitive benefit from procholinergic nicotinic stimulation. These results are the first to show that genetic differences influence the efficacy of a cognitive enhancer. Neuropsychopharmacology (2010) 35, 1090-1096; doi:I0.1038/npp.2009.2I4; published online I3 January 2010
\end{abstract}

Keywords: apolipoprotein E; nicotine; prospective memory; cognitive enhancement; cholinergic system; cognition

\section{INTRODUCTION}

The recent proliferation of research concerning 'smart drug' use in normally functioning young adults has identified a number of compounds capable of improving cognitive performance (Farah et al, 2004). A call has been made for increased research into the factors that may influence the potential for compounds to boost cognition in healthy adults given that usage of these compounds may now be surpassing associated knowledge (Greely et al, 2008). Thus far, compounds that affect different neurotransmitter systems in the brain, different cognitive domains, and different baseline profiles have been explored, but no clear cut indices of efficacy have been achieved for any of these factors (Lanni et al, 2008).

With this in mind, we sought to investigate whether genetic differences might interact with the potential for neuromodulation of cognition by putative cognitive enhancers. The most widely studied genetic variation is that associated with a common polymorphism of the apolipoprotein E (APOE) gene, which results in three alleles

\footnotetext{
*Correspondence: Dr NL Marchant, Psychology Department, University of Sussex, Pevensey Building, Brighton, East Sussex BNI 9QG, UK, Tel: + 4401273876561 , Fax: + 4401273678058 ,

E-mail: n.l.marchant@sussex.ac.uk

Received 27 April 2009; revised 24 November 2009; accepted 25 November 2009
}

$(\varepsilon 2, \varepsilon 3, \varepsilon 4)$. Emerging studies now indicate that young-adult $\varepsilon 4$ carriers may comprise a cognitive supergroup (Han and Bondi, 2008), and in fact that the well-documented negative consequences of possessing an $\varepsilon 4$ allele (eg greater risk for developing dementia, poorer cognitive aging (Corder et al, 1993; Saunders et al, 1993)) may not emerge until after the fifth decade of life (Savitz et al, 2006). Specifically, recent behavioral studies report that $\varepsilon 4$ carriers in younger life have higher IQs (Yu et al, 2000), higher educational achievement (Hubacek et al, 2001), and better performance on certain cognitive tasks (Mondadori et al, 2007) compared with their non- $\varepsilon 4$ peers. Therefore, we asked the question: does the $\varepsilon 4$ advantage in healthy young adults reduce or increase the potential for pharmacologic cognitive enhancement?

One such cognitive enhancer, nicotine, acts through cholinergic stimulation. It improves attention and memory performance in younger and older adults without a history of nicotine use (Levin et al, 2006; Robbins, 2002). In addition, it improves prospective memory (PM) in normally functioning nicotine-naive young adults (Marchant et al, 2008; Rusted and Trawley, 2006; Rusted et al, 2005). PM is a type of memory particularly relevant to everyday living and as such is a valuable indicator of real world memory capability against which to test cognitive enhancers. It is engaged when we interrupt an ongoing activity to retrieve and act on an earlier formed intention, and allows us to multi-task successfully through the day. Cognitively healthy 
older adult $\varepsilon 4$ carriers show poorer PM performance than non- $\varepsilon 4$ peers (Driscoll et al, 2005), suggesting that PM performance is a sensitive index of genetic as well as pharmacologic manipulation. Therefore, we chose this task as the primary focus of a study that co-varied genotype ( $83 / \varepsilon 3$ vs 84 carriers) and nicotine administration in normally functioning young adults.

\section{MATERIALS AND METHODS}

\section{Participants}

One-hundred and fifty-six volunteers were recruited from Sussex University. All volunteers met strict criteria for physical and psychological health, were non-smokers (with $>5$ years abstinence), had a body mass index within the normal range (18-30), and were aged $18-30$ years. APOE genotype was determined by a blood sample or buccal swab. Twenty-seven $\varepsilon 4(1 \varepsilon 2 / \varepsilon 4,2 \varepsilon 4 / \varepsilon 4,24 \varepsilon 3 / \varepsilon 4$; furthermore referred to as $\varepsilon 4$ carriers) and $29 \varepsilon 3 / \varepsilon 3$ participants (furthermore referred to as the 83 controls) returned for the full study. $\varepsilon 3 / \varepsilon 3^{\prime} s$ were chosen as it is normal practice to provide a homogenous control group representing the genotype most frequently in the general population (Rebeck et al, 1993). This $\varepsilon 4$ allelic frequency is aligned with population percentages and from other studies (eg Corder et al, 1993). Forty-four participants were Caucasian, 7 Asian, 1 Black, and 4 participants described themselves as 'mixed ethnicity.' The study was approved by the National Health Service - National Research Ethics Service. Written informed consent was obtained, and all participants were reimbursed for their time.

Participants in each group ( $\varepsilon 3 /$ placebo, $\varepsilon 3 /$ nicotine, $\varepsilon 4 /$ placebo, $\varepsilon 4 /$ nicotine) were matched on age, gender, IQ, and appropriate behavioral and physiological measures (see Table 1). Alcohol consumption was measured using the Alcohol Usage Quotient (Mehrabian and Russell, 1978), a questionnaire that provides a composite measure based on units of alcohol consumed per week, drinking rate, number of times the participant was drunk in the last 6 months, and percentage of times the participant gets drunk. Exercise was determined by self-reported number of times the participant exercised per week (Sedentary: $<1$ day of exercise, Moderate: 1-3 days, Active: $4-5$ days, Athletic: $>5$ days).

\section{Neuropsychological Assessment}

Spatial working memory (Mechaeil, 2009, unpublished thesis) was assessed during the familiarization session. Participants were instructed to remember the locations of seven rectangles presented simultaneously for $1 \mathrm{~s}$. After an $8 \mathrm{~s}$ delay, one rectangle appeared and participants decided whether the solitary rectangle was in the same location as one of the initial seven rectangles by circling either 'yes' (the rectangle is in the same location as one of the seven presented earlier) or 'no' (the rectangle is not in the same location as one of the seven presented earlier) on a trial-bytrial template. They were allotted $10 \mathrm{~s}$ to make their decision before the program progressed to the next stimuli. There were 2 practice trials and 16 experimental trials.

The National Adult Reading Test (NART; Nelson and Willison, 1991) provides an estimate of IQ and was administered as part of the baseline battery of tests. Participants were required to read 50 phonetically irregular words aloud and their responses were, individually scored as correct or incorrect based on their pronunciation. The total numbers of errors are well correlated with the Wechsler Adult Intelligence Scale-R (Nelson and Willison, 1991).

Immediate Verbal Free Recall was measured during the familiarization session and again at the end of the experimental session. Participants were instructed to complete written recall of a 20 -word list with each word presented on screen for $2 \mathrm{~s}$ with an interstimulus interval (ISI) of $1 \mathrm{~s}$. Different lists were used at the different time points, matched on frequency of occurrence, imageability, and number of syllables (Rusted, 1988).

A verbal fluency task, in which participants generate as many words as possible that begin with a certain letter within $60 \mathrm{~s}$, was included to measure 'executive functioning.' Only data from participants whose first language was English and who were in the placebo condition are reported because this task was conducted during the nicotine absorption phase (making any possible effects of nicotine ambiguous). They were given the letters ' $F$, ' $A$,' and ' $S$,' and the number of unique words for each of these letters were summed and reported in 15-s segments.

Cognitive Failures Questionnaire (CFQ; Broadbent et al, 1982 ) is self-report questionnaire that assesses four different appraisals of cognitive functioning: memory, distractibility, blunders, and naming. Participants were asked to respond to the questions using a 5-point scale (very often, quite often, occasionally, very rarely, never).

Sustained attention was measured using the Rapid Visual Information Processing (RVIP) task (Wesnes and Warburton, 1983). Single digit numbers appeared in the middle of the computer screen and participants were instructed to press spacebar each time they saw either three odd numbers or three even numbers in a row. Digits were presented for $750 \mathrm{~ms}$ with no ISI. The task lasted continuously for $5 \mathrm{~min}$ with five target sequences occurring per minute. Target hits, misses, false alarms, and correct rejections for each minute were entered into a $\mathrm{d}^{\prime}$ transformation. The $\mathrm{d}^{\prime}$ transformation minimizes the potential influence of response bias by subtracting the $z$-transformed false alarm rate from the hit rate; therefore, a higher $\mathrm{d}^{\prime}$ value indicates better performance.

Decision-making ability was measured using the ongoing task of the PM paradigm. Participants first completed this task before drug administration as a measure of 'decisionmaking' ability. They were instructed to sort a deck of 52 playing cards according to suit (Rusted et al, 2009). Each card image remained on the computer screen for $750 \mathrm{~ms}$ with an ISI of $1000 \mathrm{~ms}$ (in which the back of a playing card was displayed). Therefore, participants were allowed $1750 \mathrm{~ms}$ from stimulus onset to respond. This task was completed before drug administration.

PM was measured in the context of the ongoing decisionmaking task. In addition to completing the decision-making task, participants were told to withhold their suit-sorting responses and press spacebar if they saw a number ' 7 ' card-the PM target. There were two decks of cards comprising 104 trials in total, with 8 target cards. Therefore, 
Table I Mean Baseline Scores for Volunteers on Measured Participant Characteristics (Standard Deviations Below)

\begin{tabular}{|c|c|c|c|c|c|c|c|c|}
\hline & \multicolumn{3}{|c|}{$\varepsilon 3$ Controls } & \multicolumn{3}{|c|}{ \&4 Carriers } & \multirow{2}{*}{ Total } & \multirow{2}{*}{$p$-values } \\
\hline & Placebo $N=15$ & Nicotine $N=14$ & Total $\mathbf{N}=\mathbf{2 9}$ & Placebo $N=12$ & Nicotine $N=15$ & Total $N=\mathbf{2 7}$ & & \\
\hline Age & $\begin{array}{l}19.73 \\
1.28\end{array}$ & $\begin{array}{l}21.21 \\
3.42\end{array}$ & $\begin{array}{l}20.45 \\
2.61\end{array}$ & $\begin{array}{l}19.83 \\
1.27\end{array}$ & $\begin{array}{l}20.33 \\
1.99\end{array}$ & $\begin{array}{l}20.11 \\
1.69\end{array}$ & $\begin{array}{l}20.29 \\
2.21\end{array}$ & $H(3)=1.11, p=0.78^{a}$ \\
\hline Gender & $8 \mathrm{M} / 7 \mathrm{~F}$ & $7 \mathrm{M} / 7 \mathrm{~F}$ & $15 \mathrm{M} / 14 \mathrm{~F}$ & $7 \mathrm{M} / 5 \mathrm{~F}$ & $6 \mathrm{M} / 9 \mathrm{~F}$ & $13 \mathrm{M} / 14 \mathrm{~F}$ & $28 \mathrm{M} / 28 \mathrm{~F}$ & $\chi^{2}(3)=1.00, p=0.80$ \\
\hline Estimated $\mathrm{IQ}^{\mathrm{b}}$ & $\begin{array}{l}105.28 \\
7.76\end{array}$ & $\begin{array}{l}109.58 \\
8.46\end{array}$ & $\begin{array}{l}107.04 \\
8.15\end{array}$ & $\begin{array}{l}105.37 \\
7.52\end{array}$ & $\begin{array}{l}107.43 \\
4.74\end{array}$ & $\begin{array}{l}106.52 \\
6.07\end{array}$ & $\begin{array}{l}106.76 \\
7.04\end{array}$ & $F(3,46)=0.85, p=0.47$ \\
\hline English first language & $13 Y / 2 N$ & $9 Y / 5 N$ & $22 Y / 7 \mathrm{~N}$ & IIY/IN & $|4 Y /| N$ & $25 Y / 2 N$ & $47 Y / 9 N$ & $\chi^{2}(3)=5.6, p=0.13$ \\
\hline Baseline heart rate & $\begin{array}{l}72.93 \\
18.15\end{array}$ & $\begin{array}{l}78.93 \\
15.13\end{array}$ & $\begin{array}{l}75.83 \\
16.74\end{array}$ & $\begin{array}{l}74.50 \\
11.82\end{array}$ & $\begin{array}{l}72.60 \\
12.87\end{array}$ & $\begin{array}{l}73.44 \\
\mid 2.21\end{array}$ & $\begin{array}{l}74.68 \\
14.65\end{array}$ & $F(3,55)=0.55, p=0.65$ \\
\hline Baseline systolic blood pressure & $\begin{array}{l}110.27 \\
15.05\end{array}$ & $\begin{array}{l}105.00 \\
8.05\end{array}$ & $\begin{array}{l}107.72 \\
12.26\end{array}$ & $\begin{array}{l}109.42 \\
10.82\end{array}$ & $\begin{array}{l}107.87 \\
10.16\end{array}$ & $\begin{array}{l}108.56 \\
10.28\end{array}$ & $\begin{array}{l}108.13 \\
11.26\end{array}$ & $F(3,55)=0.58, p=0.63$ \\
\hline Baseline diastolic blood pressure & $\begin{array}{l}55.20 \\
10.56\end{array}$ & $\begin{array}{l}53.36 \\
6.40\end{array}$ & $\begin{array}{l}54.31 \\
8.70\end{array}$ & $\begin{array}{l}49.08 \\
11.26\end{array}$ & $\begin{array}{l}53.13 \\
6.29\end{array}$ & $\begin{array}{l}51.33 \\
8.90\end{array}$ & $\begin{array}{l}52.88 \\
8.84\end{array}$ & $F(3,55)=1.1, p=0.36$ \\
\hline Body mass index & $\begin{array}{l}24.13 \\
3.41\end{array}$ & $\begin{array}{l}23.03 \\
3.44\end{array}$ & $\begin{array}{l}23.60 \\
3.41\end{array}$ & $\begin{array}{l}21.05 \\
1.85\end{array}$ & $\begin{array}{l}23.36 \\
2.82\end{array}$ & $\begin{array}{l}22.33 \\
2.66\end{array}$ & $\begin{array}{l}22.99 \\
3.11\end{array}$ & $F(3,55)=2.48, p=0.07$ \\
\hline Family $\mathrm{H} \times$ of dementia & $|4 N /| Y$ & I3N/IY & $27 N / 2 Y$ & I2N/OY & $12 N / 3 Y$ & $24 N / 3 Y$ & $51 N / 5 Y$ & $\chi^{2}(3)=3.59, p=0.31$ \\
\hline Exercise $^{c}$ & 2S/9M/3Ac/lAt & $2 S / I \mid M / I A c / 0 A t$ & 4S/20M/4Ac/lAt & 3S/5M/4Ac/0At & 3S/9M/2Ac/lAt & $6 \mathrm{~S} / 14 \mathrm{M} / 6 \mathrm{Ac} / \mathrm{AAt}$ & IOS/34M/I0Ac/2At & $\chi^{2}(9)=6.56, p=0.68$ \\
\hline Alcohol use quotient & $\begin{array}{l}47.48 \\
43.59\end{array}$ & $\begin{array}{l}23.74 \\
23.42\end{array}$ & $\begin{array}{l}36.02 \\
36.75\end{array}$ & $\begin{array}{l}37.48 \\
29.39\end{array}$ & $\begin{array}{l}39.59 \\
28.91\end{array}$ & $\begin{array}{l}38.65 \\
28.58\end{array}$ & $\begin{array}{l}37.29 \\
32.80\end{array}$ & $F(3,55)=1.33, p=0.28$ \\
\hline
\end{tabular}

${ }^{a}$ Equal variances not assumed.

${ }^{\mathrm{b}}$ On the basis of data from participants for whom English is their first language

'Exercise classifications per week: $\mathrm{S}=$ sedentary ( $<$ I day of exercise); $M=$ moderate ( $1-3$ days); $A c=$ active ( $4-5$ days); At = athletic $(>5$ days). 
PM targets constituted roughly $7.5 \%$ of trials. Participants received these instructions before drug administration and completed the task $\sim 15$ min after using the nasal spray.

\section{Design and Procedure}

Participants visited the laboratory 1-7 days before the experimental session to become familiar with the nasal spray, complete the spatial working memory task, immediate verbal free recall task, and practice the RVIP task.

Baseline physiological and mood measures were taken at the beginning of the experimental session, followed by instructions and practice of the ongoing decision-making task. On completion, participants received the added PM instructions. They then self-administered the nasal spray and immediately performed the verbal fluency task, NART, and CFQ. Completion of these tasks required 12-15 min, the time necessary for nicotine to reach peak plasma concentration (Schneider et al, 1996). Physiological and mood measures were again taken. They then completed the ongoing/PM task followed by restatement of the ongoing/ PM instructions to confirm compliance. Four participants incorrectly reported these instructions and were removed from analyses of this task. A 5-min version of the RVIP task was then performed, followed by a second immediate verbal free recall task. Final physiological and mood measures were taken. Participants also reported whether they believed they had received nicotine or not, and were subsequently debriefed and discharged from the laboratory.

\section{APOE Genotyping and Data Analysis}

APOE genotype was determined after a standardized protocol using a polymerase chain reaction-based assay that uses the Afl III and HaeII restriction enzymes to distinguish among the alleles (Ossendorf and Prellwitz, 2000).

\section{Statistical Analyses}

Statistical analyses were conducted using Statistical Package of Social Sciences (SPSS 14) software and an alpha level of 0.05 was used to interpret significant differences in the results. In all cases, genotype and drug represented between subjects factors, and time represented the within subject factor. Pre-nicotine analyses were conducted using independent $t$-tests (genotype) or a mixed design analysis of variance (ANOVA; genotype $\times$ time). Post-nicotine analyses were conducted using between subjects ANOVAs (genotype $\times$ drug) or mixed design ANOVAs (genotype $\times$ drug $\times$ time). Post hoc analyses were performed using independent $t$-tests with Bonferroni corrections reported when appropriate. Means with \pm 1 standard error of the mean are reported.

All of the analyses examining the cognitive measures were run using only Caucasian participants (see Supplementary Table), and also comparing only $\varepsilon 3 / \varepsilon 3$ and $\varepsilon 3 / \varepsilon 4$ participants. The same pattern of results emerged for these smaller groups as those reported in the results section, which used the entire sample.

\section{RESULTS}

\section{Pre-nicotine Assessments}

$\varepsilon 4$ carriers were faster at the 'decision-making' task (measured in milliseconds, ms; $472 \pm 8$ ) than 83 controls (499 $\pm 8 ; t_{(54)}=2.38, p=0.02$ ), while maintaining equal levels of accuracy $\left(t_{(34.52)}=1.51, P=0.14\right.$, equal variances not assumed; Figure 1a).

Examination of the verbal fluency task revealed a main effect of time, with participants producing fewer words over the course of the task $\left(F_{(3,63)}=103.44, p<0.001\right)$. There was no main effect of genotype for overall performance on the 60 -s task $\left(t_{(22)}=1.72, p=0.1\right)$, but there was a time $\times$ genotype interaction $\left(F_{(3,63)}=3.18, p=0.03\right)$. $\varepsilon 4$ carriers $(19.2 \pm 1.72)$ produced more words in the first quarter of the task than $\varepsilon 3$ controls $\left(14.85 \pm .77 ; t_{(21)}=2.5, p=0.02\right)$, and while they continued to produce more words in each subsequent quarter, the differences were not significant (Figure 1b).

For the other cognitive tasks administered before nicotine administration, no differences were found between gene groups: spatial working memory $\left(t_{(53)}=0.19, p=0.85\right)$ and immediate verbal recall $\left(t_{(54)}=0.71, p=0.48\right)$. In addition, no differences emerged on any of the factors from the CFQ: memory $\left(t_{(54)}=0.15, p=0.25\right)$, distractibility $\left(t_{(54)}=0.4\right.$,
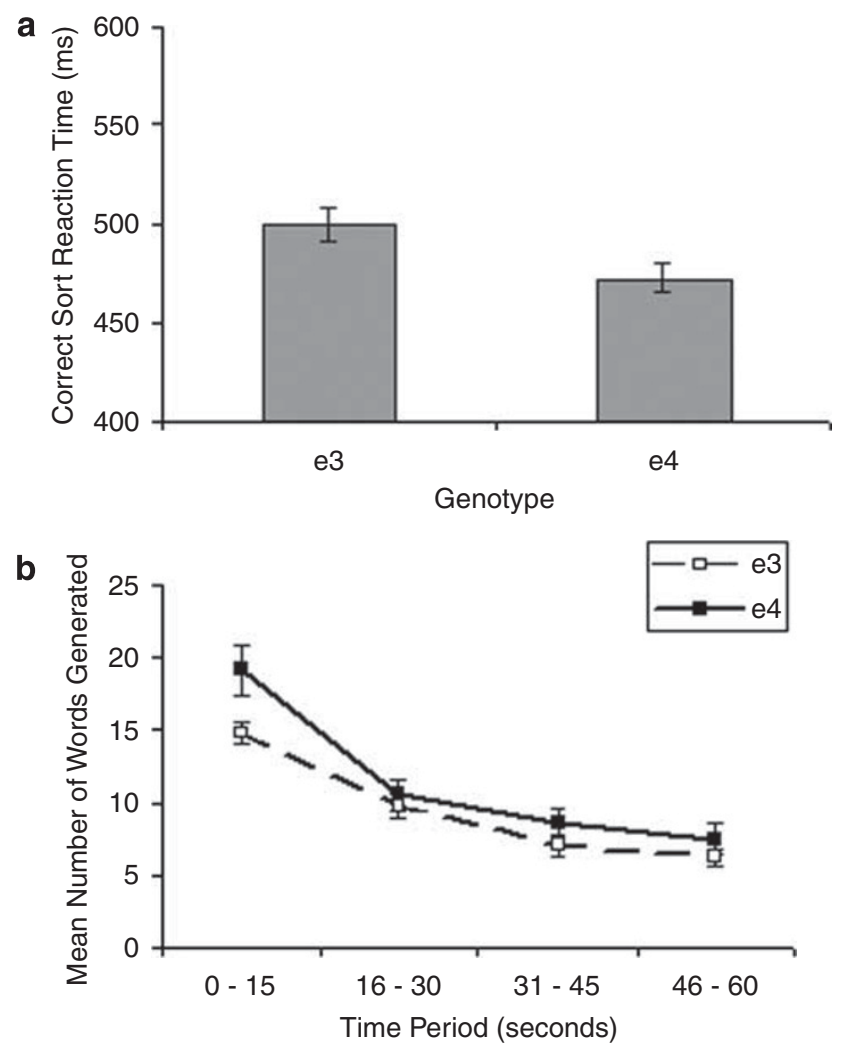

Figure I Genotype differences on cognitive measures that require frontal cortex involvement. Means and error bars indicating SEM are displayed. (a) Response times (measured in milliseconds) in a decisionmaking task. $\varepsilon 4$ carriers responded significantly faster than $\varepsilon 3$ controls $\left(t_{(54)}=2.38, p=0.02\right)$. (b) The number of words is produced using a task of verbal fluency, measured in $15 \mathrm{~s}$ segments. All participants declined in word generation over time $\left(F_{(3,63)}=103.44, p<0.00 \mathrm{I}\right)$, with a time $\times$ gene interaction $\left(F_{(3,63)}=3.18, p=0.03\right)$. This result was driven by $\varepsilon 4$ carriers producing more words in the first $15 \mathrm{~s}\left(t_{(21)}=2.5, p=0.02\right)$. 
$p=0.69)$, blunders $\left(t_{(54)}=0.31, p=0.76\right)$, and naming $\left(t_{(54)}=0.89, p=0.38\right)$.

After nasal spray administration, participants completed the ongoing task of sorting the playing cards by suit, but this time with the embedded PM component. The $\varepsilon 4$ carriers were again faster at the ongoing task than $\varepsilon 3$ controls $\left(F_{(1,48)}=5.11, p=0.03\right)$, with no main effect of drug or interaction (Figure 2a). There was a near significant main effect of genotype on levels of accuracy for the ongoing task $\left(F_{(1,48)}=3.87, p=0.055\right)$, with an additional near significant interaction with drug $\left(F_{(1,48)}=3.41\right.$, $p=0.07$; Figure $2 \mathrm{~b}$ ). Given the investigative nature of the study, post hoc analyses were conducted. The $\varepsilon 4 /$ nicotine group $(95.24 \pm 0.84)$ was significantly more accurate than
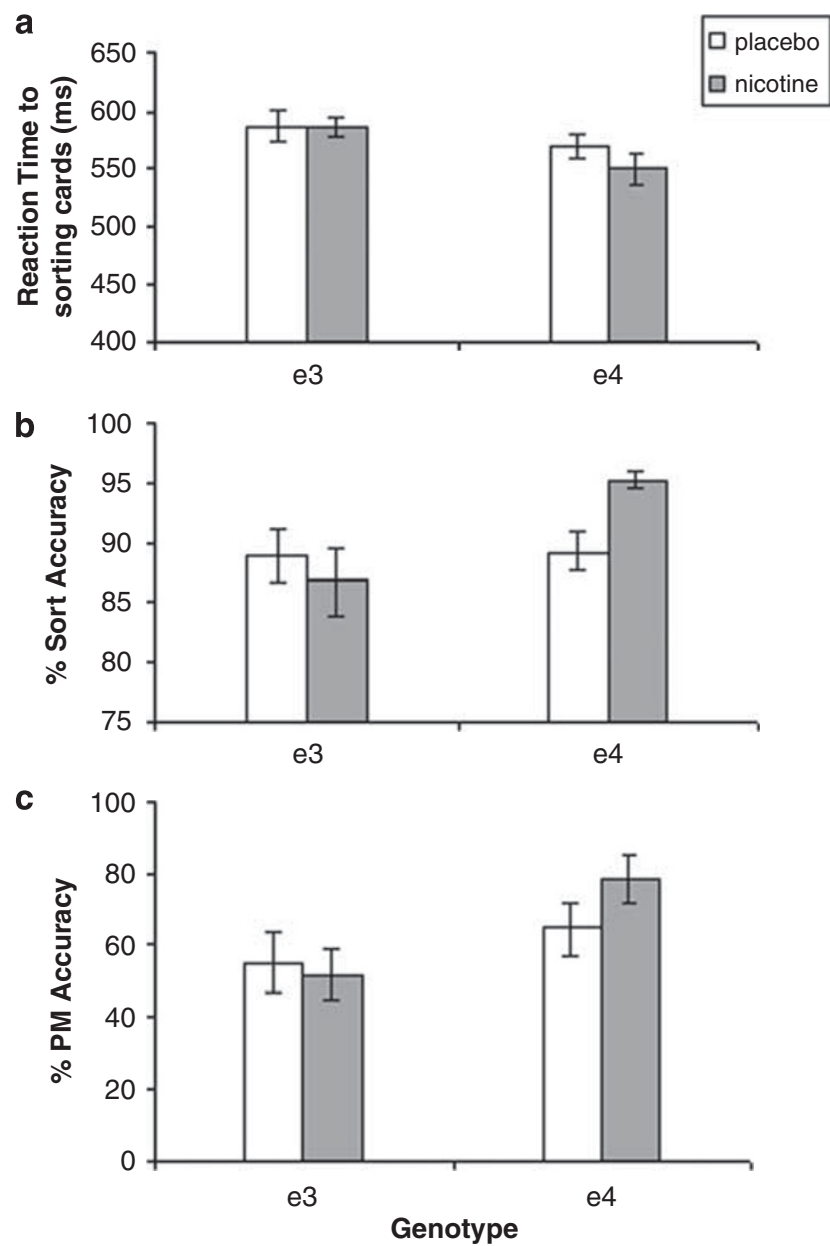

Figure 2 Cognitive measures showing different effects of nicotine on performance by $\varepsilon 4$ carriers and $\varepsilon 3$ controls. Means and error bars indicating SEM are displayed. (a) Response times (measured in milliseconds) in a decision-making task. The $\varepsilon 4$ carriers were significantly faster than $\varepsilon 3$ controls $\left(F_{(1,48)}=5.11, p=0.03\right)$. No significant effects of nicotine or interactions were observed. (b) The $\varepsilon 4 /$ nicotine group was more accurate in the decision-making task than all other groups ( $\varepsilon 4 /$ placebo group: $t_{(21)}=3.1, p=0.005, \varepsilon 3 /$ nicotine group: $t_{(23)}=2.55, p=0.02$, $\varepsilon 3 /$ placebo group: $\left.t_{(17.55)}=2.59, p=0.02\right)$. (c) Prospective memory (PM) accuracy was measured by the number of correct responses to the PM cue to during the decision-making task. $\varepsilon 4$ carriers showed superior PM accuracy $\left(F_{(I, 48)}=5.78, \quad p=0.02\right)$, specifically the $\varepsilon 4 /$ nicotine group was more accurate than the $\varepsilon 3 /$ nicotine group $\left(t_{(23)}=2.77, p=0.01\right)$ and the $\varepsilon 3 /$ placebo group $\left(t_{(23.79)}=2.25, p=0.03\right)$, but not the $\varepsilon 4 /$ placebo group $\left(t_{(21)}=1.39, p=0.18\right)$. the $\varepsilon 4 /$ placebo group $\left(89.21 \pm 1.7 ; t_{(21)}=3.1, p=0.005\right)$, the $\varepsilon 3 /$ nicotine group $\left(86.73 \pm 2.87 ; t_{(23)}=2.55, p=0.02\right)$, and $\varepsilon 3 /$ placebo group $\left(88.94 \pm 2.29 ; t_{(17.55)}=2.59, p=0.02\right.$, equal variances not assumed). There was no difference between the $\varepsilon 3 /$ placebo and $\varepsilon 3 /$ nicotine groups, or $\varepsilon 4 /$ placebo and $\varepsilon 3 /$ placebo groups. After using the Bonferroni correction $(P<0.01)$, the only difference to remain significant was between $\varepsilon 4 /$ nicotine and $\varepsilon 4 /$ placebo groups.

$\mathrm{PM}$ was measured by the number of times the volunteer pressed the spacebar to register the detection of the PM target, regardless of whether they had first made a response to the ongoing task $($ maximum $=8$ ). No main effects or interactions were found between groups when analyzing reaction time. A main effect of gene was found for PM target percent accuracy $\left(F_{(1,48)}=5.78, p=0.02\right)$, with $\varepsilon 4$ carriers $(71.2 \pm 4.8)$ surpassing 83 controls $(53.45 \pm 5.39)$. Post hoc analyses indicated that the $\varepsilon 4 /$ nicotine group was significantly more accurate than the $\varepsilon 3 /$ nicotine group $\left(t_{(23)}=2.77, \quad p=0.01\right), \quad$ and the $\varepsilon 3 /$ placebo group $\left(t_{(23.79)}=2.25, p=0.03\right.$; equal variances not assumed $)$, but not the $\varepsilon 4 /$ placebo group $\left(t_{(21)}=1.39, p=0.18\right.$; Figure $\left.2 \mathrm{c}\right)$. There was no difference between the $\varepsilon 3 /$ placebo group and the $\varepsilon 3 /$ nicotine group. After using the Bonferroni correction $(P<0.01)$, the only difference to remain significant was between $\varepsilon 4 /$ nicotine and $\varepsilon 3 /$ nicotine groups. Thus, not only did $\varepsilon 4$ carriers show superior decision-making and PM performance, this advantage was augmented by the cognitive enhancer, nicotine. In fact, nicotine seemed to benefit only $\varepsilon 4$ carriers.

Sustained attention was measured using the RVIP task. A $\mathrm{d}^{\prime}$ transformation revealed a main effect of time on task $\left(F_{(4,208)}=17.44, p<0.001\right)$, which was qualified by a three way (time $\times$ gene $\times$ drug) interaction $\left(F_{(4,208)}=3.95\right.$, $p=0.004)$. Post hoc analyses revealed that the $\varepsilon 4 /$ placebo group were more accurate $(3.77 \pm 0.11)$ than the $\varepsilon 3 /$ placebo group $(3.0 \pm 0.28)$ in minute $1\left(t_{(17.83)}=2.58, p=0.02\right.$; equal variances not assumed) and in minute $2\left(t_{(25)}=2.4\right.$, $p=0.02)$. When corrected for multiple comparisons using the Bonferroni post hoc analysis $(p<0.01)$, these differences did not remain significant. A $\chi^{2}$ analysis was conducted to identify the number of people who were unable to correctly identify $50 \%$ of the targets. Significantly more 83 controls recorded $50 \%$ or less hits (11 out of 29 ) than $\varepsilon 4$ carriers ( 2 out of $27 ; \chi_{(1)}^{2}=7.31, p=0.007$ ). There was no differential effect of nicotine on this measure. Response times (ms) to correctly identified targets were not differentiated by gene or drug. The results from this task indicate that $\varepsilon 4$ carriers were better able to sustain their attention, and showed an early advantage in accuracy.

Physiological measures and subjective assessments of mood were collected at baseline, after nicotine absorption, and on completion of the experimental tasks. Mean arterial blood pressure increased in a linear manner over the course of the experiment $\left(F_{(2,104)}=4.85, p=0.01\right)$. There were no main effects of drug or gene, and no interactions. Heart rate showed no main effects or interactions. Mood was assessed using two standardized measures: the Profile of Mood States (McNair et al, 1971) and Thayer's measures of alert and tense arousal (Thayer, 1978). Both measures registered a decline in arousal/alertness across the time course of the study, independent of gene type or drug condition $(p s<0.02)$. There were no other main effects or interactions. 
These findings are consistent with earlier reports using nicotine nasal sprays (Marchant et al, 2008).

\section{DISCUSSION}

The potential of putative cognitive enhancers and of select genetic polymorphisms to boost performance in normally functioning adults is an area of growing interest. We sought to investigate the extent of the $\varepsilon 4$ advantage in young adults across a broad coverage of cognitive domains, and also, using a double-blind placebo-controlled study, to explore the interactive effect of APOE genotype and the cognitive enhancer, nicotine. The results from these cognitive tasks indicate that possession of an $\varepsilon 4$ allele produces domainspecific advantages rather than a global cognitive advantage. Specifically, $\varepsilon 4$ carriers excelled in decision making, $\mathrm{PM}$ performance, and verbal fluency, all tasks that require frontal lobe involvement, but not on spatial memory or word recall. Thus, we argue that, early in life, frontally mediated tasks seem to benefit from possession of an $\varepsilon 4$ allele. Indeed, these findings support emerging literature showing cognitive superiority of young $\varepsilon 4$ carriers (Alexander et al, 2007; Han and Bondi, 2008; Mondadori et al, 2007). In our study, this cognitive superiority was not explained by an alternate hypothesis, namely that $\varepsilon 4$ carriers were consciously compensating for poorer memory skills with metacognitive strategies. $\varepsilon 4$ and $\varepsilon 3$ participants showed similar self-reported abilities in cognitive functioning as measured by the CFQ.

In addition, the manipulation of performance by the introduction of a cognitive enhancer revealed that even though $\varepsilon 4$ carriers already showed a cognitive advantage over their e3 counterparts, nicotine potentiated this advantage on measures of decision making and PM performance. These results indicate the capacity for cognitive performance in young healthy volunteers to be modified both by pharmacologic and genetic factors, and, critically, for those effects to be cumulative. The result is in contrast with recent suggestions (Muller et al, 2004; Randall et al, 2005) that cognitive enhancement in younger adults is most likely to be achieved when baseline performance is below average.

Our results, then, add further support for the emerging view that while the $\varepsilon 4$ allele produces detrimental consequences in later life, it in fact confers a cognitive advantage in younger adulthood. These findings support the recent proposition of APOE $\varepsilon 4$ antagonistic pleitropy (Han and Bondi, 2008; Wright et al, 2003), whereby the $\varepsilon 4$ variant might have contrasting effects across the lifespan. Our results suggest that this labile cognitive profile of $\varepsilon 4$ carriers may be related to and influenced by the integrity of the cholinergic system. Older carriers of the $\varepsilon 4$ allele have significantly less choline (the precursor to acetylcholine) and less choline acetyltransferase (the enzyme involved in converting choline to acetylcholine) activity than matched non- $\varepsilon 4$ carriers (Poirier et al, 1995). These deficiencies certainly contribute to the more rapid cognitive decline in older $\varepsilon 4$ carriers and may explain why, in our study, $\varepsilon 4$ carriers were more receptive to the cholinergic agonist, nicotine. Our findings offer new implications for the antagonistic pleitropy theory and suggest the possible molecular basis or locus for the opposing effects of APOE across the lifespan. A similar advantage for carriers of the APOE polymorphism from other putative cognitive enhancers would implicate a non-cholinergic explanation, however.

Knowing that possession of an $\varepsilon 4$ allele increases susceptibility to dementia and cognitive deterioration in later life, our results raise the question of how long this advantage in younger life might last, and whether cholinergic stimulation in earlier life might delay or hasten this decline. These results thus have implications for the development of cognitive-enhancing drugs for healthy individuals and treatment approaches for dementia. Specifically, individual differences may have a significant function in the efficacy of these compounds across the lifespan. This study provides the first study to cross the $\varepsilon 4$ polymorphism with a pharmacological manipulation in young adult. The sample size, while typical of pharmacological manipulation studies, may be considered small in relation to genetic studies. As such, it may be viewed as a preliminary step in the field of gene $x$ drug interaction. It argues firmly, however, for the value of further research into the individual factors that may moderate the effects of putative cognitive modulators across the lifespan.

\section{ACKNOWLEDGEMENTS}

This work was supported by a Sussex University D.Phil. studentship and an Overseas Research Scheme Award to the first author. We thank McNeil AB, Helsingborg, Sweden for providing the nasal sprays.

\section{DISCLOSURE}

Naji Tabet has received research grants (unrelated to this study) from Pfizer and Novartis. He also received consultation and/or speaker fees from Pfizer, Eli Lilly, AstraZenca, Shire, Novartis, and Lundbeck. Natalie Marchant, Sarah King, and Jennifer Rusted have no conflicts of interest to disclose.

\section{REFERENCES}

Alexander DM, Williams LM, Gatt JM, Dobson-Stone C, Kuan SA, Todd EG et al (2007). The contribution of apolipoprotein E alleles on cognitive performance and dynamic neural activity over six decades. Biol Psychol 75: 229-238.

Broadbent DE, Cooper PF, FitzGerald P, Parkes KR (1982). The cognitive failures questionnaire (CFQ) and its correlates. $\mathrm{Br} \mathrm{J}$ Clin Psychol 21(Part 1): 1-16.

Corder EH, Saunders AM, Strittmatter WJ, Schmechel DE, Gaskell PC, Small GW et al (1993). Gene dose of apolipoprotein E type 4 allele and the risk of Alzheimer's disease in late onset families. Science 261: 921-923.

Driscoll I, McDaniel MA, Guynn MJ (2005). Apolipoprotein E and prospective memory in normally aging adults. Neuropsychology 19: $28-34$.

Farah MJ, Illes J, Cook-Deegan R, Gardner H, Kandel E, King P et al (2004). Neurocognitive enhancement: what can we do and what should we do? Nat Rev Neurosci 5: 421-425.

Greely H, Sahakian B, Harris J, Kessler RC, Gazzaniga M, Campbell $P$ et al (2008). Towards responsible use of cognitive-enhancing drugs by the healthy. Nature 456: 702-705. 
Han SD, Bondi MW (2008). Revision of the apolipoprotein E compensatory mechanism recruitment hypothesis. Alzheimers Dement 4: 251-254.

Hubacek JA, Pitha J, Skodova Z, Adamkova V, Lanska V, Poledne R (2001). A possible role of apolipoprotein E polymorphism in predisposition to higher education. Neuropsychobiology 43: 200-203.

Lanni C, Lenzken SC, Pascale A, Del Vecchio I, Racchi M, Pistoia F et al (2008). Cognition enhancers between treating and doping the mind. Pharmacol Res 57: 196-213.

Levin ED, McClernon FJ, Rezvani AH (2006). Nicotinic effects on cognitive function: behavioral characterization, pharmacological specification, and anatomic localization. Psychopharmacology 184: 523-539.

Marchant NL, Trawley S, Rusted JM (2008). Prospective memory or prospective attention: physiological and pharmacological support for an attentional model. Int J Neuropsychopharmacol 11: 401-411.

McNair D, Lorr M, Droppleman L (1971). Profile of Mood States. Edits/ Educational and Industrial Testing Service Inc.: San Diego, CA.

Mechaeil R (2009). Exploring the Effects of Losartan on Cognition. Unpublished doctoral dissertation, University of Sussex: Brighton.

Mehrabian A, Russell J (1978). A questionnaire measure of habitual alcohol use. Psychol Rep 43: 803-806.

Mondadori CR, de Quervain DJ, Buchmann A, Mustovic H, Wollmer MA, Schmidt CF et al (2007). Better memory and neural efficiency in young apolipoprotein E epsilon4 carriers. Cereb Cortex 17: 1934-1947.

Muller U, Steffenhagen N, Regenthal R, Bublak P (2004). Effects of modafinil on working memory processes in humans. Psychopharmacology (Berl) 177: 161-169.

Nelson HE, Willison JR (1991). National Adult Reading Test (NART). Second edn. NFER-NELSON NFER-NELSON: Windsor, Berks.

Ossendorf M, Prellwitz W (2000). Rapid and easy apolipoprotein E genotyping using an improved PCR-RFLP technique. Qiagen News 1: 11-13.

Poirier J, Delisle MC, Quirion R, Aubert I, Farlow M, Lahiri D et al (1995). Apolipoprotein E4 allele as a predictor of cholinergic deficits and treatment outcome in Alzheimer disease. Proc Natl Acad Sci USA 92: 12260-12264.

Randall DC, Shneerson JM, File SE (2005). Cognitive effects of modafinil in student volunteers may depend on IQ. Pharmacol Biochem Behav 82: 133-139.
Rebeck GW, Reiter JS, Strickland DK, Hyman BT (1993). Apolipoprotein E in sporadic Alzheimer's disease: allelic variation and receptor interactions. Neuron 11: 575-580.

Robbins TW (2002). The 5-choice serial reaction time task: behavioural pharmacology and functional neurochemistry. Psychopharmacology 163: 362-380.

Rusted JM (1988). Dissociative effects of scopolamine on working memory in healthy young volunteers. Psychopharmacology 96: 487-492.

Rusted JM, Sawyer R, Jones C, Trawley SL, Marchant NL (2009). Positive effects of nicotine on cognition: the deployment of attention for prospective memory. Psychopharmacology 202: 93-102.

Rusted JM, Trawley S (2006). Comparable effects of nicotine in smokers and nonsmokers on a prospective memory task. Neuropsychopharmacology 31: 1545-1549.

Rusted JM, Trawley S, Heath J, Kettle G, Walker H (2005). Nicotine improves memory for delayed intentions. Psychopharmacology 182: 355-365.

Saunders AM, Strittmatter WJ, Schmechel D, George-Hyslop PH, Pericak-Vance MA, Joo SH et al (1993). Association of apolipoprotein E allele epsilon 4 with late-onset familial and sporadic Alzheimer's disease. Neurology 43: 1467-1472.

Savitz J, Solms M, Ramesar R (2006). Apolipoprotein E variants and cognition in healthy individuals: a critical opinion. Brain Res Rev 51: 125-135.

Schneider NG, Lunell E, Olmstead RE, Fagerstrom KO (1996). Clinical pharmacokinetics of nasal nicotine delivery. A review and comparison to other nicotine systems. Clin Pharmacokinet 31: $65-80$.

Thayer RE (1978). Toward a psychological theory of multidimensional activation (arousal). Motiv Emot 2: 1-34.

Wesnes K, Warburton DM (1983). Effects of smoking on rapid information processing performance. Neuropsychobiology 9: 223-229.

Wright RO, Hu H, Silverman EK, Tsaih SW, Schwartz J, Bellinger D et al (2003). Apolipoprotein $\mathrm{E}$ genotype predicts 24-month bayley scales infant development score. Pediatr Res 54: 819-825.

Yu YW, Lin CH, Chen SP, Hong CJ, Tsai SJ (2000). Intelligence and event-related potentials for young female human volunteer apolipoprotein E epsilon4 and non-epsilon4 carriers. Neurosci Lett 294: 179-181.

Supplementary Information accompanies the paper on the Neuropsychopharmacology website (http://www.nature.com/npp) 